\title{
The Voltage Stabilizing Control Strategy of Off-Grid Microgrid Cluster Bus Based on Adaptive Genetic Fuzzy Double Closed-Loop Control
}

\author{
Yu Zhang $\mathbb{D}$, Hongwan Yang, and Peng Wang \\ College of Mechanical and Control Engineering, Guilin University of Technology, Guilin 541004, China \\ Correspondence should be addressed to Yu Zhang; 17316606@qq.com
}

Received 6 January 2021; Revised 11 May 2021; Accepted 31 May 2021; Published 9 June 2021

Academic Editor: Luigi Piegari

Copyright (c) $2021 \mathrm{Yu}$ Zhang et al. This is an open access article distributed under the Creative Commons Attribution License, which permits unrestricted use, distribution, and reproduction in any medium, provided the original work is properly cited.

\begin{abstract}
In the off-grid microgrid cluster, the energy storage device is mainly charged and discharged to maintain the stability of the bus voltage and the system power balance. Generally, the voltage and current double closed-loop control and fuzzy control are adopted for the energy storage converter. The traditional double closed-loop control parameters and the scale factor and quantization factor in fuzzy control cannot be adjusted in real time during system operation, resulting in slower dynamic response and weak anti-interference ability of the system. In response to the above problems, this paper proposes an adaptive genetic fuzzy double closed-loop control, which can adjust the PI control parameters in real time by adjusting the quantization factor and the scale factor to optimize the control effect. The simulation platform is built in MATLAB/Simulink and the simulation results show that the adaptive genetic fuzzy double closed-loop control combines the advantages of fuzzy and PI control. Under different working conditions, the system has not only a fast dynamic response, small overshoot, and strong anti-interference ability but also good robustness.
\end{abstract}

\section{Introduction}

With the increasing energy demand, energy shortage, and environmental pollution caused by energy utilization, the use of renewable and clean energy such as solar energy as distributed power sources has gained people's favor and rapid development. It has solved energy shortages and environmental pollution. And the power supply and distribution problems in remote areas have greatly saved costs [1-3]. In the development of distributed power sources, in order to ensure the reliability of power supply and power quality for users, some scholars have proposed the concept of the microgrid. The microgrid is a collection of distributed power sources, energy conversion devices, loads, and protection devices. The power distribution system can realize self-control and management $[4,5]$. As an extension of the single microgrid structure and function expansion, the microgrid cluster uses the interconnected operation of multiple single microgrids to improve the reliability of the power supply of the system. It can run in two different working modes, on-grid and off-grid [6-9]. In the off-grid microgrid cluster, the bus voltage is the only criterion to measure the stability of the system. However, affected by the randomness of photovoltaic power generation and the dynamic changes of the load, it will cause disturbances in the system bus voltage. In response to the problem of how to maintain the stability of the system, mainly through the energy storage device connected by the bidirectional DC-DC converter (BDC) and the busbar to charge and discharge, the bus voltage stability and power balance of the microgrid cluster system are maintained. When the energy in the microgrid is insufficient, the energy storage device provides insufficient energy, and when the microgrid is surplus, the energy storage device stores the surplus energy [10-12].

At present, the control of the energy storage converters in the microgrid is very important. Generally, voltage and current double closed-loop control is adopted. The traditional double closed-loop control uses the bus voltage as the 
outer loop control and the inductor current of the converter as the inner loop control. Applying classic control theory, the microgrid cluster can operate stably through PI control and adjustment. However, the parameters of the double closed-loop control cannot be dynamically adjusted, the dynamic response is slow, and the ability to restrain external disturbances and self-recovery is poor. Therefore, it is not suitable for nonlinear time-varying off-grid microgrids cluster control [13-17].

Since fuzzy control is suitable for nonlinear and timevarying systems, and its robustness is good, it is aimed at the shortcomings of traditional double closed-loop control; the improvement of double closed-loop control is proposed. Fuzzy control is used in the voltage outer loop control to set the PI control parameters on the outer loop in real time to achieve optimal control effects. However, the quantization factor, scale factor, fuzzy rule, and membership function in fuzzy control cannot be adjusted dynamically. At the same time, the control rules and control parameters of fuzzy control are based on experience, which has a certain degree of subjectivity and lack rationality for nonlinear systems. There are certain limitations in optimizing PI control parameters, resulting in system dynamic response and anti-interference ability not improved [18-21]. Literature [22] proposed an adaptive fuzzy control, which has two types of indirect adaptive fuzzy control and direct adaptive fuzzy control, but both of them modify the fuzzy control parameters by operating an external mechanism. The process is more troublesome and the system error is relatively large, which is not suitable for the nonlinear microgrid cluster system. In view of the improvement of fuzzy control, some scholars proposed to use intelligent algorithms to adjust the quantization factor and scale factor in fuzzy control to optimize the fuzzy output. Literature [23-25] proposed genetic fuzzy control, which can optimize the output value of fuzzy control in real time and seek the optimal solution by encoding, selecting, crossing, and mutating the quantization factor and scale factor in fuzzy control. However, it did not consider the problem that when all individuals in the system tend to a state and stop evolving, it is difficult to obtain a global optimal solution. Therefore, when the energy storage converter adopts genetic fuzzy double closed-loop control, the dynamic response speed of the microgrid cluster and the anti-interference ability to the outside world are not very ideal.

This paper proposes an adaptive genetic fuzzy double closed-loop control for energy storage converters in a microgrid cluster. By adjusting the quantization factor and the scale factor, the PI control parameters can be adjusted in real time to optimize the control effect and improve the dynamic response speed of the microgrid cluster and the anti-interference ability to the outside world. The simulation results show that the adaptive genetic fuzzy double closed-loop control combines the advantages of fuzzy and PI control. Under different working conditions, the system has not only a fast dynamic response, small overshoot, and strong anti-interference ability but also good robustness.

\section{Topological Structure and Circuit Diagram}

2.1. Topological Structure Diagram. The topology of the DC microgrid cluster is shown in Figure 1. The microgrid cluster is composed of two DC microgrids interconnected. Each microgrid in the microgrid cluster contains photovoltaic cells, storage batteries, and loads. The photovoltaic cells and storage batteries are, respectively, connected to the bus through the Boost converter and the bidirectional DC-DC converter, and the load is connected to the bus through the Buck converter.

2.2. Circuit Structure Diagram. The energy storage device plays an important role in maintaining the power balance of the microgrid cluster and the stability of the bus voltage. It can be used as a power source for compensating energy, or as a load for storing energy. The structure of the off-grid DC microgrid cluster in this article is shown in Figure 2.

In Figure $2, i_{\mathrm{pv} \_d c 1}, i_{\text {load1 } 1}, i_{\mathrm{b} \_\mathrm{dcl}}$, and $i_{\mathrm{b} 1}$ are, respectively, the output current of the photovoltaic cells of the microgrid 1 in the microgrid cluster through the Boost converter, the input current of the Buck converter, the output current of the battery through $\mathrm{BDC}$, and the input current of the isolation BDC; $L_{\mathrm{pv} 1}, L_{1}, L_{\mathrm{bat1}}$, and $L_{\mathrm{b}}$ are, respectively, the energy storage inductances of the Boost converter, Buck converter, $\mathrm{BDC}$, and isolated $\mathrm{BDC}$ of microgrid $1 ; U_{1}$ and $C_{\mathrm{b} 1}$ are, respectively, the bus voltage and filter capacitor of microgrid $1 ; i_{\mathrm{pv} \_\mathrm{dc} 2}, i_{\text {load2 }}, i_{\mathrm{b} \_\mathrm{dc} 2}$, and $i_{\mathrm{b} 2}$ are, respectively, the output current of the photovoltaic cells of the microgrid 2 in the microgrid cluster through the Boost converter, the input current of the Buck converter, the output current of the battery through the $\mathrm{BDC}$, and the isolated $\mathrm{BDC}$ input current; $L_{\mathrm{pv} 2}, L_{2}$, and $L_{\mathrm{bat} 2}$ are, respectively, the inductance of Boost converter, Buck converter, and BDC of microgrid 2; and $U_{2}$ and $C_{\mathrm{b} 2}$ are the bus voltage and filter capacitance of microgrid 2, respectively. The current relations of microgrid 1 and microgrid 2 are obtained from Kirchhoff's current law as follows:

$$
\begin{gathered}
C_{b 1} \frac{\mathrm{d} U_{1}}{\mathrm{~d} t}=i_{p v_{-} d c 1}+i_{b_{-} d c 1}-i_{\text {load } 1}-i_{b 1}, \\
C_{b 2} \frac{\mathrm{d} U_{2}}{\mathrm{~d} t}=i_{p v_{-} d c 2}+i_{b_{-} d c 2}-i_{\text {load } 2}-i_{b 2} .
\end{gathered}
$$

In the above equations (1) and (2), the positive and negative of $i_{\mathrm{b} \_\mathrm{dcl}}$ and $i_{\mathrm{b} \_\mathrm{dc} 2}$ are related to the working status of the energy storage devices in microgrid 1 and microgrid 2. When the values of $i_{\mathrm{b}_{\mathrm{d}} \mathrm{dc1}}$ and $i_{\mathrm{b} \_\mathrm{dc} 2}$ are positive, the energy storage device discharges and acts as a power source. When the values of $i_{\mathrm{b} \_\mathrm{dc} 1}$ and $i_{\mathrm{b} \_\mathrm{dc} 2}$ are negative, the energy storage device is charged and acts as a load. This paper mainly adopts adaptive genetic fuzzy double closedloop control for the energy storage converters in the microgrid cluster and suppresses the fluctuation of the DC bus voltage by controlling the charging and discharging of the battery to ensure the safe and stable operation of the system. 


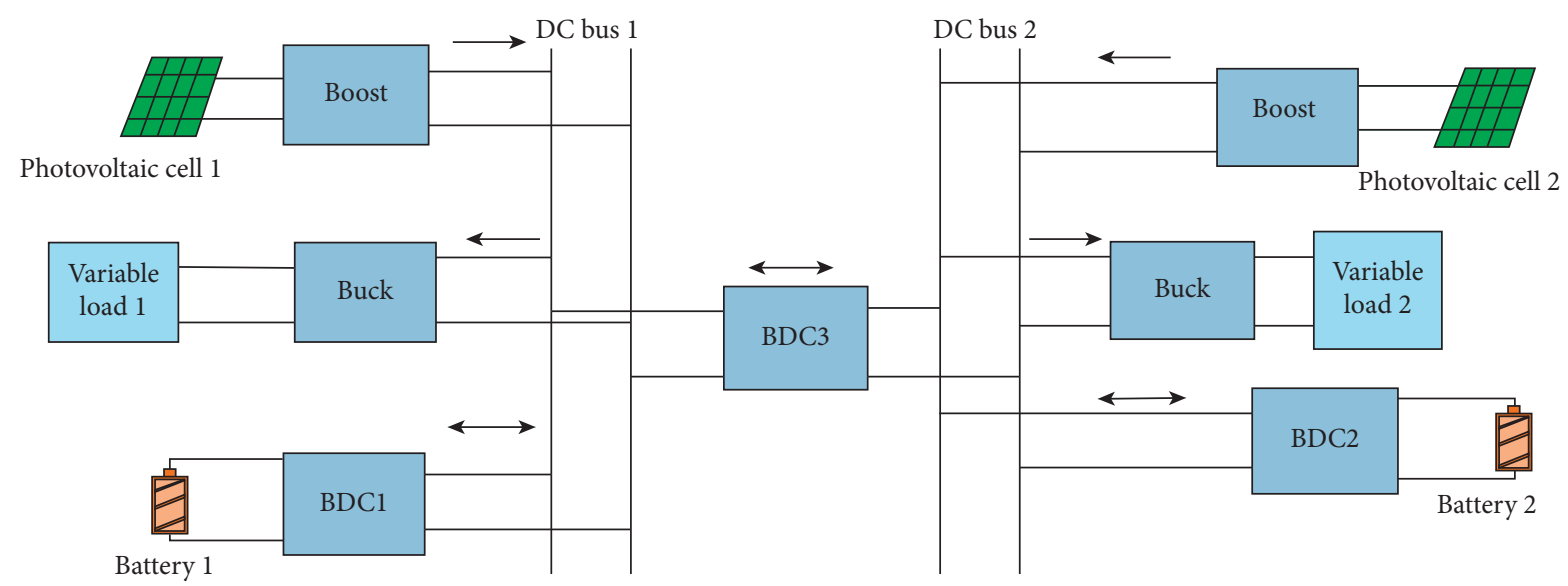

FIgURE 1: Topology of DC microgrid cluster.

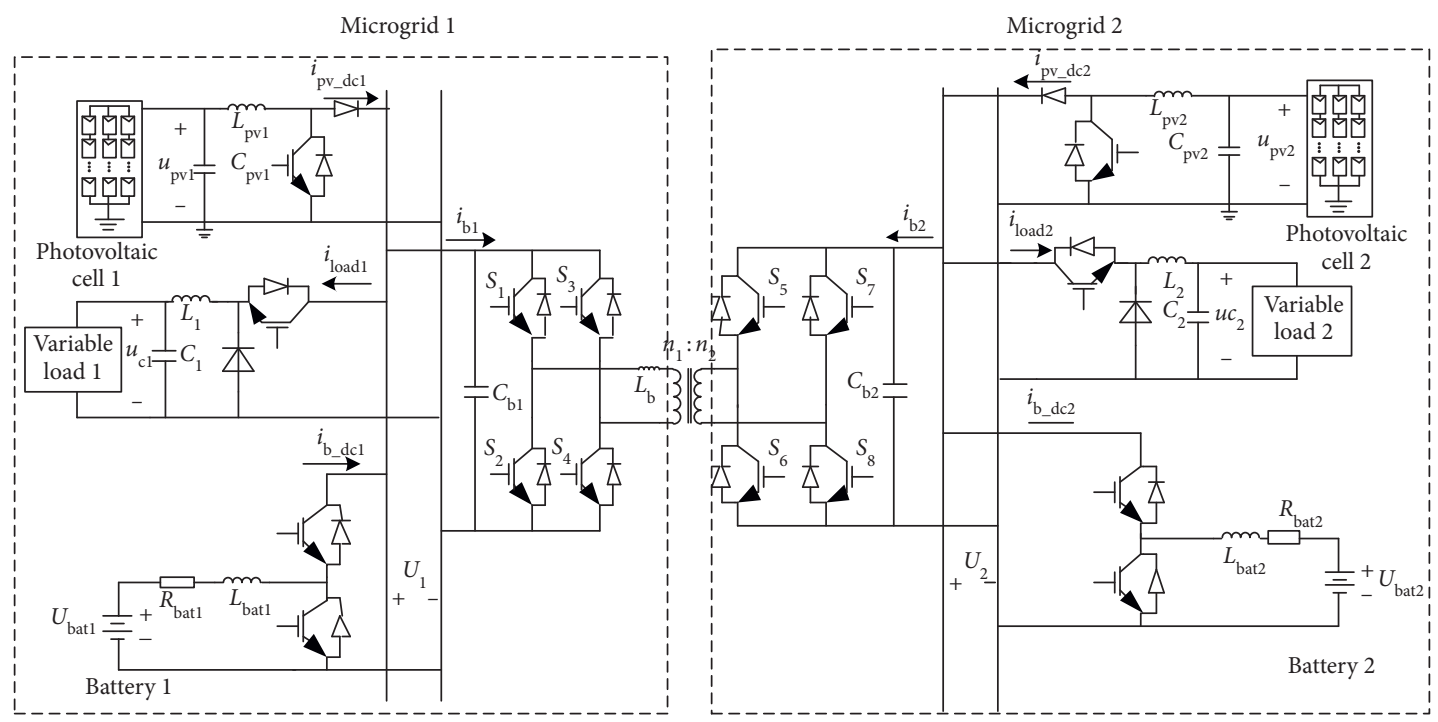

FIgURE 2: DC microgrid cluster structure.

\section{Control Strategy}

3.1. Fuzzy Double Closed-Loop Control. The traditional microgrid cluster energy storage converter generally adopts fuzzy double closed-loop control, and the structure of fuzzy double closed-loop control is shown in Figure 3.

In Figure 3, according to the difference between the reference value $U^{*}$ of the bus voltage and the actual value $U$, the deviation $e_{1}$ and the deviation change rate $e c_{1}$ are obtained, the deviation $e_{1}$ and the deviation change rate $e c_{1}$ obtain $e$ and $e c$ through the quantization factors $k_{\mathrm{e}}$ and $k_{\mathrm{ec}}$, and then $e$ and $e c$ obtain the correction values $\Delta K_{\mathrm{p}}$ and $\Delta K_{\mathrm{i}}$ of the proportional and integral parameters through the fuzzy logic controller to adjust the control parameters of the controller in real time, where $k_{\mathrm{e}}, k_{\mathrm{ec}}, d k_{\mathrm{p}}$, and $d k_{\mathrm{i}}$ are fixed values. The setting formula is as follows, where $K_{p}$ and $K_{i}$ are the real-time proportional and integral coefficients of the controller and $K_{p}^{*}$ and $K_{i}^{*}$ are the initial proportional and integral control coefficients of the controller:

$$
\left\{\begin{array}{l}
K_{p}=K_{p}^{*}+\Delta K_{p} * d k_{p} \\
K_{i}=K_{i}^{*}+\Delta K_{i} * d k_{i} .
\end{array}\right.
$$

The design of fuzzy control is mainly to determine the fuzzy rules and membership functions. The commonly used membership functions mainly include Z-shaped, S-shaped, triangle, bell-shaped, and Gaussian. The triangular membership function is simple in form, high in sensitivity, and fast in response.

In this paper, the membership functions of $e, e c, \Delta K_{\mathrm{p}}$, and $\Delta K_{\mathrm{i}}$ are all triangular, and the fuzzy domains are all $[-5$, 5]. The fuzzy subsets of $e, e c, \Delta K_{\mathrm{p}}$, and $\Delta K_{\mathrm{i}}$ are all $\{\mathrm{NB}, \mathrm{NM}$, NS, Z, PS, PM, PB\}, The function is shown in Figure 4.

According to the fuzzy control membership function and control theory, the fuzzy rules of $\Delta K_{p}$ and $\Delta K_{i}$ are inferred, as shown in Tables 1 and 2.

The fuzzy regular surface diagram of fuzzy input $e$ and $e c$ and output $\Delta K_{p}$ and $\Delta K_{i}$ in this paper is shown in Figure 5. 


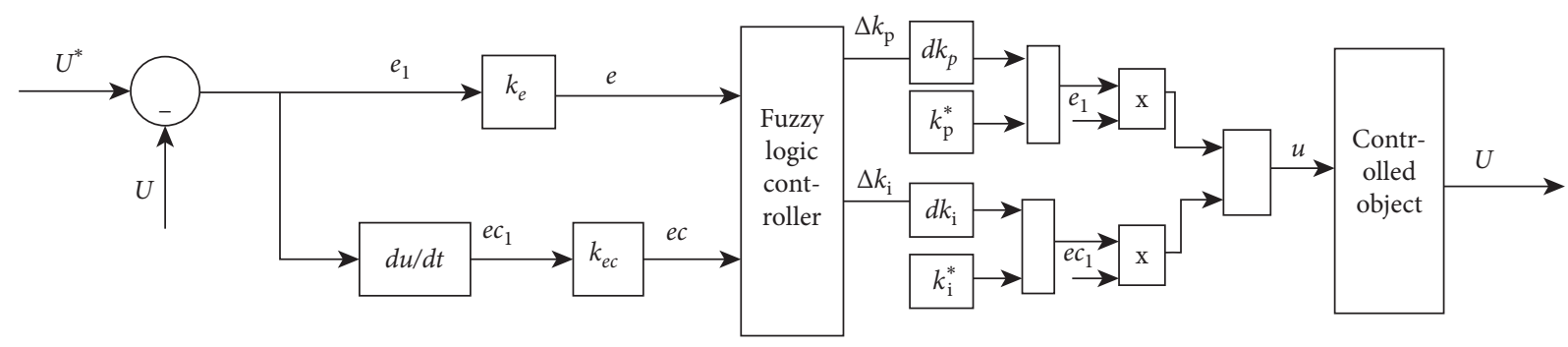

FIgURE 3: Fuzzy double closed-loop control structure diagram.

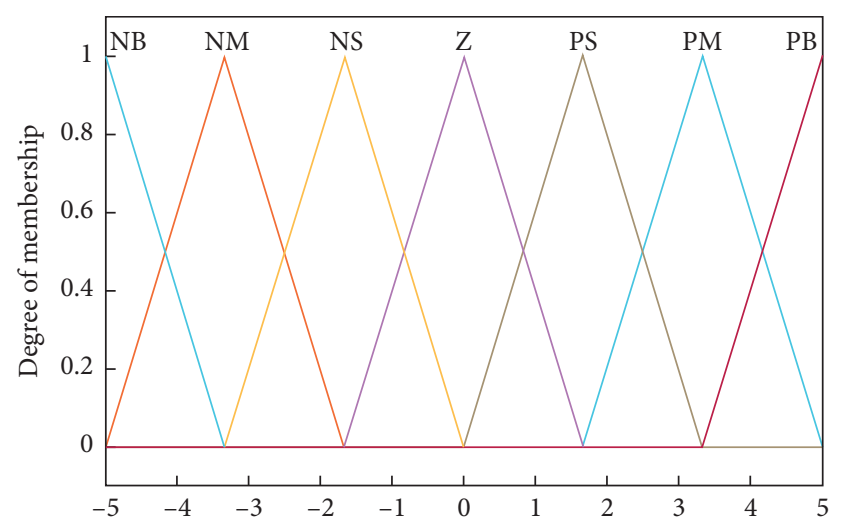

Figure 4: The membership function graph of $e, e c, \Delta K_{p}$, and $\Delta K_{i}$.

TABLE 1: $\Delta K_{p}$ of fuzzy control rules.

\begin{tabular}{|c|c|c|c|c|c|c|c|}
\hline \multirow{3}{*}{$e$} & \multicolumn{7}{|c|}{$e c$} \\
\hline & & & & $\triangle k_{p}$ & & & \\
\hline & $\mathrm{NB}$ & NM & NS & $\mathrm{ZO}$ & PS & PM & $\mathrm{PB}$ \\
\hline NB & $\mathrm{PB}$ & $\mathrm{PB}$ & $\mathrm{PM}$ & $\mathrm{PM}$ & PS & $\mathrm{ZO}$ & $\mathrm{ZO}$ \\
\hline NM & PB & PB & $\mathrm{PM}$ & PS & PS & $\mathrm{ZO}$ & NS \\
\hline NS & $\mathrm{PM}$ & $\mathrm{PM}$ & $\mathrm{PM}$ & PS & $\mathrm{ZO}$ & NS & NS \\
\hline $\mathrm{ZO}$ & $\mathrm{PM}$ & $\mathrm{PM}$ & PS & $\mathrm{ZO}$ & NS & $\mathrm{NM}$ & NM \\
\hline PS & PS & PS & $\mathrm{ZO}$ & NS & NS & $\mathrm{NM}$ & NM \\
\hline $\mathrm{PM}$ & PS & $\mathrm{ZO}$ & NS & $\mathrm{NM}$ & NM & $\mathrm{NM}$ & NB \\
\hline $\mathrm{PB}$ & $\mathrm{ZO}$ & $\mathrm{ZO}$ & NM & NM & NM & NB & NB \\
\hline
\end{tabular}

TABLE 2: $\Delta K_{\mathrm{i}}$ of fuzzy control rules.

\begin{tabular}{|c|c|c|c|c|c|c|c|}
\hline \multirow{3}{*}{$e$} & \multicolumn{7}{|c|}{$e c$} \\
\hline & & & & $\triangle k_{i}$ & & & \\
\hline & $\mathrm{NB}$ & $\mathrm{NM}$ & NS & $\mathrm{ZO}$ & PS & $\mathrm{PM}$ & $\mathrm{PB}$ \\
\hline NB & $\mathrm{NB}$ & NB & NM & $\mathrm{NM}$ & NS & $\mathrm{ZO}$ & $\mathrm{ZO}$ \\
\hline NM & $\mathrm{NB}$ & NB & NM & NS & NS & $\mathrm{ZO}$ & $\mathrm{ZO}$ \\
\hline NS & NB & NM & NS & NS & $\mathrm{ZO}$ & PS & PS \\
\hline $\mathrm{ZO}$ & NM & NM & NS & $\mathrm{ZO}$ & PS & $\mathrm{PM}$ & $\mathrm{PM}$ \\
\hline PS & NM & NS & $\mathrm{ZO}$ & PS & PS & $\mathrm{PM}$ & $\mathrm{PM}$ \\
\hline $\mathrm{PM}$ & $\mathrm{ZO}$ & $\mathrm{ZO}$ & PS & PS & $\mathrm{PM}$ & $\mathrm{PB}$ & $\mathrm{PB}$ \\
\hline PB & $\mathrm{ZO}$ & $\mathrm{ZO}$ & PS & PM & $\mathrm{PM}$ & $\mathrm{PB}$ & $\mathrm{PB}$ \\
\hline
\end{tabular}

3.2. Adaptive Genetic Fuzzy Double Closed-Loop Control. Aiming at the situation that the scale factor and quantization factor in the fuzzy double closed-loop control cannot be adjusted in real time, this paper proposes an adaptive genetic fuzzy double closed-loop control, and its control structure is shown in Figure 6.

In Figure 6, the adaptive genetic algorithm directly optimizes the quantization factors $k_{e}$ and $k_{e c}$ and the scale factors $d k_{p}$ and $d k_{i}$ to find the global optimal $K_{p}$ and $K_{i}$ in real time. The implementation of adaptive genetic algorithm is as follows:

(i) Determine the coding scheme: the genetic algorithm has multiple encodings such as binary, Gray, permutation, and real number encoding. Here, the genetic algorithm encoding adopts the binary encoding composed of $\{0,1\}$ set. $k_{e}, k_{e c}, d k_{p}$, and $d k_{i}$ all adopt 8-bit binary encoding, respectively. The number of samples is Size $=40$.

(ii) Determination of fitness function: the genetic algorithm performs an algorithm optimization search based on individual fitness value. It basically does not use external environment information in optimization search; therefore, it is very important when selecting fitness function. It determines the convergence speed of the algorithm and whether the algorithm can search for the best solution. To optimize the three elements of stability, speed, and precision of the control system, the performance index function shown in the following formula is generally selected:

$$
J=\int_{0}^{\infty}\left(\omega_{1}|m(t)|+\omega_{2} u^{2}(t)\right) \mathrm{d} t+\omega_{3} t_{u} .
$$

The optimization algorithm used in this paper has designed a penalty function. When the system error has an overshoot, the overshoot is an optimal index of the system. This purpose can effectively avoid overshoot. At this time, the optimal index function is expressed as the following formula:

$$
J=\int_{0}^{\infty}\left(\omega_{1}|m(t)|+\omega_{2} u^{2}(t)+\omega_{4}|m y(t)|\right) \mathrm{d} t+\omega_{3} t_{u}
$$

In the above formula, $u(t)$ is the self-tuning output; $\omega_{1}, \omega_{2}, \omega_{3}$, and $\omega_{4}$ are the weight, where $\omega_{1}=0.9, \omega_{2}=0.001, \omega_{3}=2.0$, and $\omega_{4}=100 ; t_{u}$ is the rise time; $m(t)$ is the system error; $m y(t)=y(t)-y(t-1)$; and $y(t)$ are the output of the controlled object. Here, the reciprocal of the 


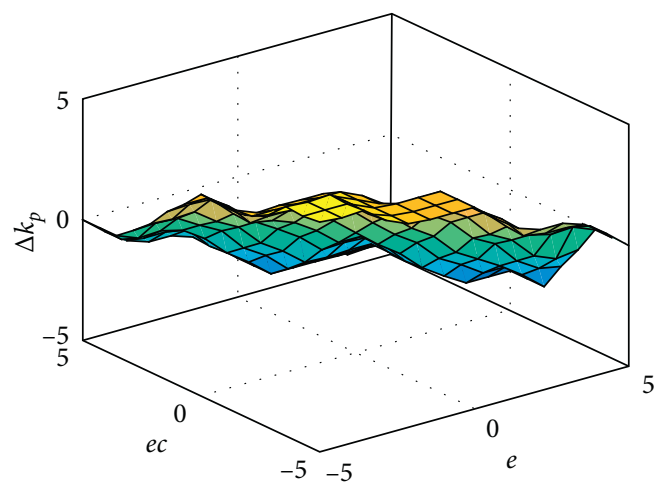

(a)

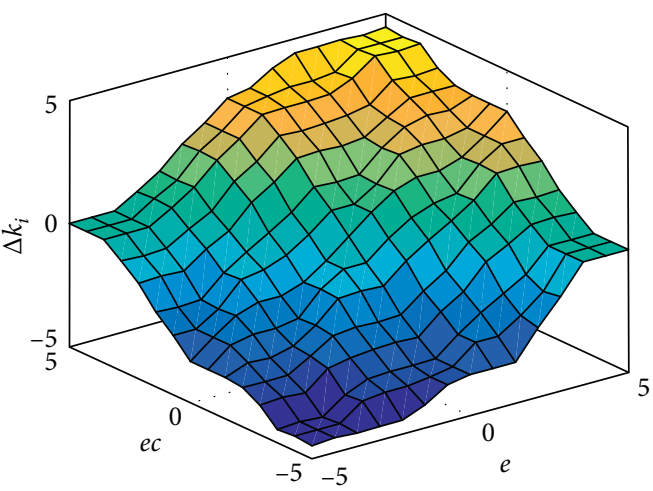

(b)

FIGURE 5: Fuzzy input and output rule surface. (a) Input and output $\Delta K_{p}$ surface graph. (b) Input and output $\Delta K_{i}$ surface graph.

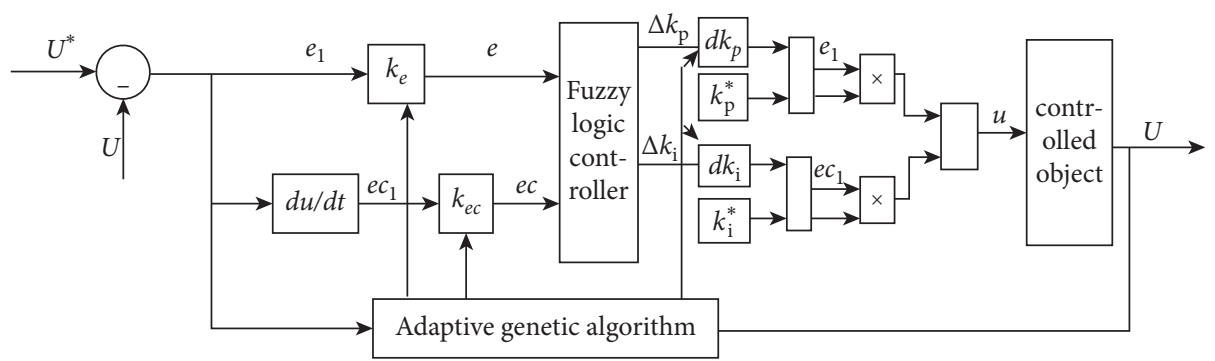

FIGURE 6: Control structure of adaptive genetic fuzzy double closed loop.

objective function is used to represent the fitness function, namely, $F=(1 / J)$.

(iii) Choice: the selection process is to eliminate some individuals that do not meet the requirements according to the fitness value of each body, and the individuals that are not eliminated can be passed on to the next generation. The proportional selection method is used here, and the relevant expression is as follows:

$$
p_{x}=\frac{f_{x}}{\sum_{k=1}^{N} f_{k}} .
$$

In the previous equation, $N$ is the number of individuals in the population; $f_{x}$ is the fitness value of individual $x ; p_{x}$ is the probability of individual $x$ being selected.

This paper adopts the optimal individual retention strategy and the optimal individual out-of-group preservation strategy based on proportional selection: the optimal individual of one generation is directly copied to the next generation to participate in further evolution, and the fitness value is compared with the external variable temp of the group. If it is greater than temp, temp is replaced by the optimal individual and its fitness value; otherwise, it remains unchanged.

(iv) Crossover and mutation: in the traditional genetic algorithm, the control parameters do not change, and the system is prone to "premature," which weakens the shrinkage efficiency of the algorithm. In this paper, the crossover probability $P_{c}$ and mutation probability $P_{\mathrm{m}}$ always change dynamically, as shown in the following equation:

$$
\left\{\begin{array}{l}
P_{c}=\frac{1}{1-\exp \left(-k_{1} \cdot \Delta\right)}, \\
P_{m}=\frac{1}{1+\exp \left(-k_{2} \cdot \Delta\right)}+1 .
\end{array}\right.
$$

In the above formula, $k_{1}$ and $k_{2}$ are the initial values of $P_{c}$ and $P_{m}$, respectively; $k_{1}$ and $k_{2}$ are greater than 0 ; this article takes $k_{1}=0.7, \quad k_{2}=0.01$; $\Delta=F_{t \text { max }}-\bar{F}_{t \text { max }}$, where $F_{t \text { max }}$ is the fitness of the largest individual; and $\bar{F}_{t \max }$ represents the average fitness of individuals whose fitness is greater than the average fitness. During the evolution of the population, due to $\Delta$ being constantly changing, $P_{c}$ and $P_{m}$ are also dynamically adjusted.

\section{Simulation Analysis}

According to the off-grid DC microgrid cluster in Figure 2, a simulation model is built in MATLAB/Simulink, and the simulation parameters are shown in Table 3.

In order to study the dynamic performance of the bus voltage during the three transient processes of initial power-on, load sudden increase, and load sudden decrease when the energy storage converter adopts fuzzy double 
TABLe 3: System simulation parameters.

\begin{tabular}{lccc}
\hline Parameter & DC microgrid 1 system & Bidirectional isolated DC-DC converter & DC microgrid 2 system \\
\hline DC bus voltage $(\mathrm{V})$ & 500 & & 650 \\
Battery rated voltage $(\mathrm{V})$ & 200 & & 200 \\
DC bus capacitance $(\mu \mathrm{F})$ & 1000 & & 1000 \\
Rated capacity of battery $(\mathrm{Ah})$ & 500 & 500 \\
Output voltage of photovoltaic cell $(\mathrm{V})$ & 240 & & 240 \\
Load resistance $(\mathrm{R})$ & 4 & & 30 \\
Rated power of DC motor $(\mathrm{W})$ & & 600 & 30 \\
Rated voltage of DC motor $(\mathrm{V})$ & & 200 & 24 \\
Rated current of DC motor $(\mathrm{A})$ & & 500 & 2.1 \\
Inductance $(\mu \mathrm{H})$ & & $500: 650$ & \\
Primary capacitance $\mathrm{C}_{1}(\mu \mathrm{F})$ & & & \\
Secondary side capacitance $\mathrm{C}_{2}(\mu \mathrm{F})$ & & & \\
Transformation ratio $N 1: N 2$ & & & \\
\hline
\end{tabular}

closed-loop control and adaptive genetic fuzzy double closed-loop control, respectively, the following work is performed as a simulation of the situation:

Working condition 1: microgrid 1 is connected to a resistance of $4 \mathrm{ohms}$ at $1.5 \mathrm{~s}$, and the obtained waveforms are shown in Figures 7-10.

Figures 7 and 9 are the bus voltage diagrams of microgrid 1 and microgrid 2 in fuzzy double closed-loop and adaptive genetic fuzzy double closed-loop, respectively. Figures 8 and 10 are, respectively, enlarged views of three parts of initial power-on, load sudden increase, and load sudden decrease in Figures 7 and 9.

It can be seen from Figure 8 that when the energy storage converter adopts fuzzy double closed-loop control at the initial power-on, the maximum overshoot of the bus voltage is $22.1 \mathrm{~V}$. After multiple oscillation adjustments, it stabilizes to $500 \mathrm{~V}$ in about $1.3 \mathrm{~s}$. When adopting adaptive genetic fuzzy double closed-loop control, the maximum overshoot of the bus voltage is $1.2 \mathrm{~V}$, there is no oscillation phenomenon, and it stabilizes to $500 \mathrm{~V}$ in about $0.9 \mathrm{~s}$. When the load suddenly increases, the bus voltage drops. When the energy storage converter adopts fuzzy double closed-loop control, the bus voltage drops to $486.7 \mathrm{~V}$ instantly. There is an overshoot phenomenon when it recovers and the maximum overshoot is $9.6 \mathrm{~V}$. At the same time, after multiple oscillation adjustments, it stabilizes to $500 \mathrm{~V}$ at about $2.85 \mathrm{~s}$. When the energy storage converter adopts adaptive genetic fuzzy double closed-loop control, the bus voltage drops to 493.2 V instantly, and there is an overshoot phenomenon during the recovery process. The overshoot is $0.6 \mathrm{~V}$, there is no oscillation, and it stabilizes to $500 \mathrm{~V}$ at about $2.3 \mathrm{~s}$. When the load is suddenly reduced, the bus voltage suddenly increases. When the energy storage converter adopts fuzzy double closed-loop control, the maximum overshoot of the bus voltage is $29.6 \mathrm{~V}$. After multiple oscillation adjustments, it stabilizes to $500 \mathrm{~V}$ in about $3.95 \mathrm{~s}$. When the energy storage converter adopts adaptive genetic fuzzy double closed-loop control, the maximum overshoot of the bus voltage is $18.2 \mathrm{~V}$, there is no oscillation phenomenon during the recovery process, and it stabilizes to $500 \mathrm{~V}$ in about $3.25 \mathrm{~s}$.

It can be seen from Figure 10 that when the energy storage converter adopts fuzzy double closed-loop control at the initial power-on, the maximum overshoot of the bus

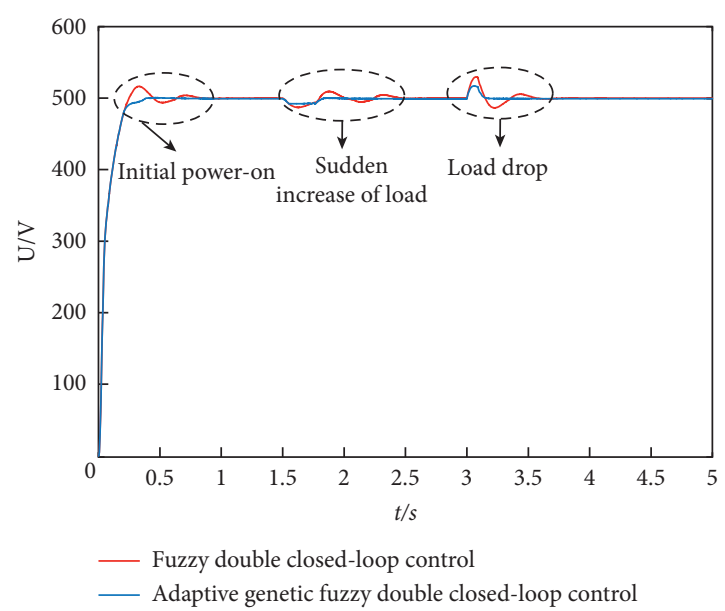

FIgURE 7: Microgrid 1 bus voltage diagram.

voltage is $15.2 \mathrm{~V}$. After oscillation adjustment, it stabilizes to $650 \mathrm{~V}$ in about $1 \mathrm{~s}$. When adopting adaptive genetic fuzzy double closed-loop control, the maximum overshoot of the bus voltage is $0.9 \mathrm{~V}$. There is no oscillation during the recovery process, and it stabilizes to $650 \mathrm{~V}$ in about $0.75 \mathrm{~s}$. When the load increases suddenly, the energy storage converter adopts fuzzy double closed-loop control, and the maximum overshoot of the bus voltage is $3.5 \mathrm{~V}$. After multiple oscillation adjustments, it stabilizes to $650 \mathrm{~V}$ in about $2.6 \mathrm{~s}$. When the energy storage converter adopts adaptive genetic fuzzy double closed-loop control, the maximum overshoot of the bus voltage is $1.2 \mathrm{~V}$, and there is no oscillation during the recovery process, and it stabilizes to $650 \mathrm{~V}$ in about $2.31 \mathrm{~s}$. When the load is suddenly reduced, the energy storage converter adopts fuzzy double closed-loop control, and the overshoot of the bus voltage is $2.2 \mathrm{~V}$. After oscillation adjustment, it stabilizes to $650 \mathrm{~V}$ in about $3.8 \mathrm{~s}$. When the energy storage converter adopts adaptive genetic fuzzy double closed-loop control, the overshoot of the bus voltage is $-0.8 \mathrm{~V}$. There is no oscillation occurring during the recovery process, and it stabilizes to $650 \mathrm{~V}$ in about $3.4 \mathrm{~s}$.

Working condition 2: microgrid 2 is connected to a resistance of $15 \mathrm{ohms}$ at $1.5 \mathrm{~s}$, and the obtained waveforms are shown in Figures 11-14. 


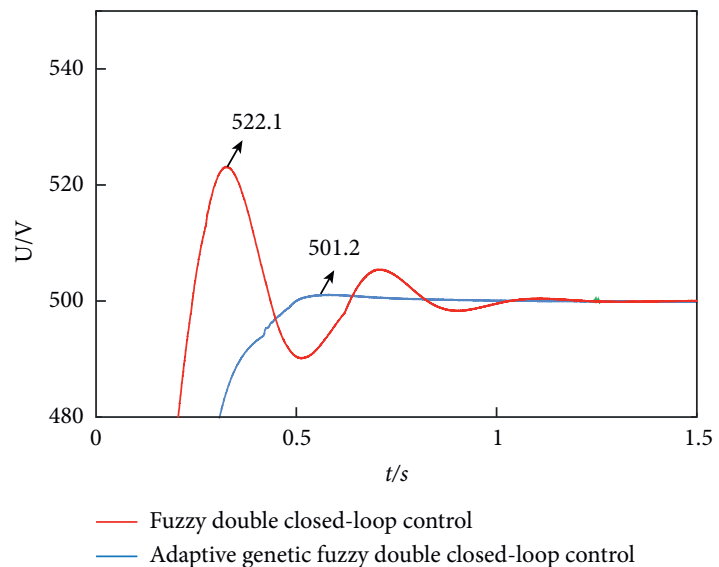

(a)

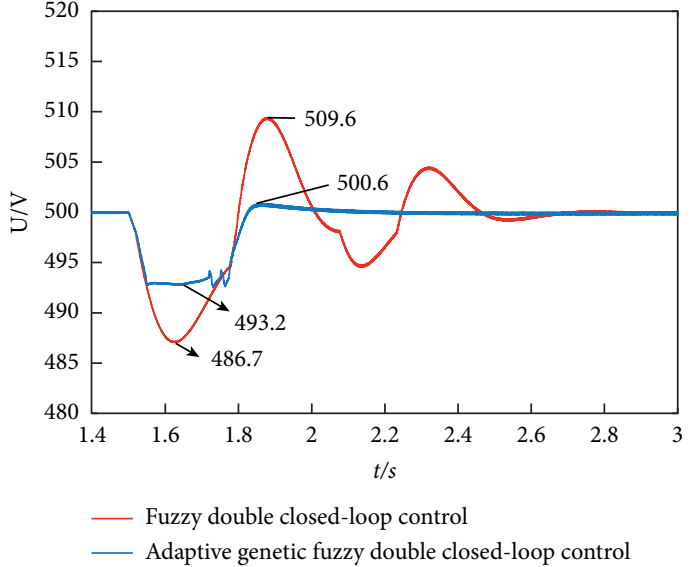

(b)

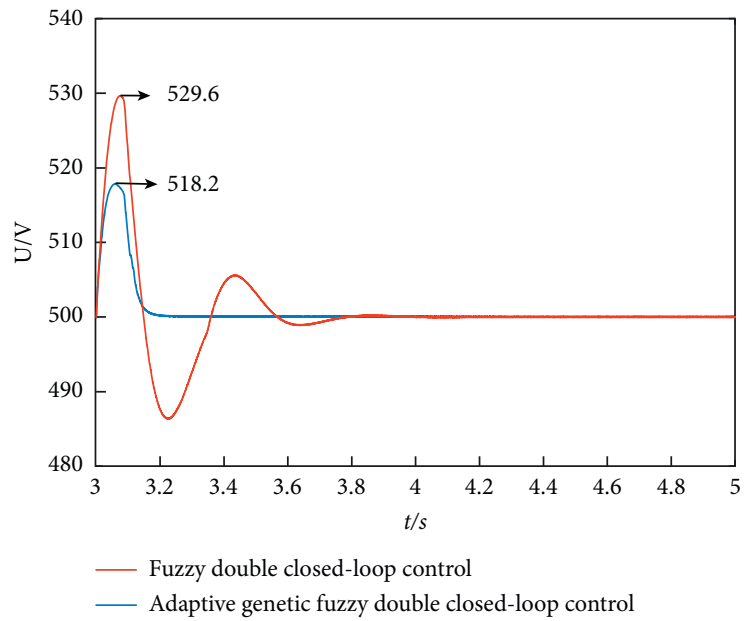

(c)

Figure 8: Voltage comparison of microgrid 1 bus. (a) Initial power-on. (b) Sudden increase of load. (c) A sudden drop in load.

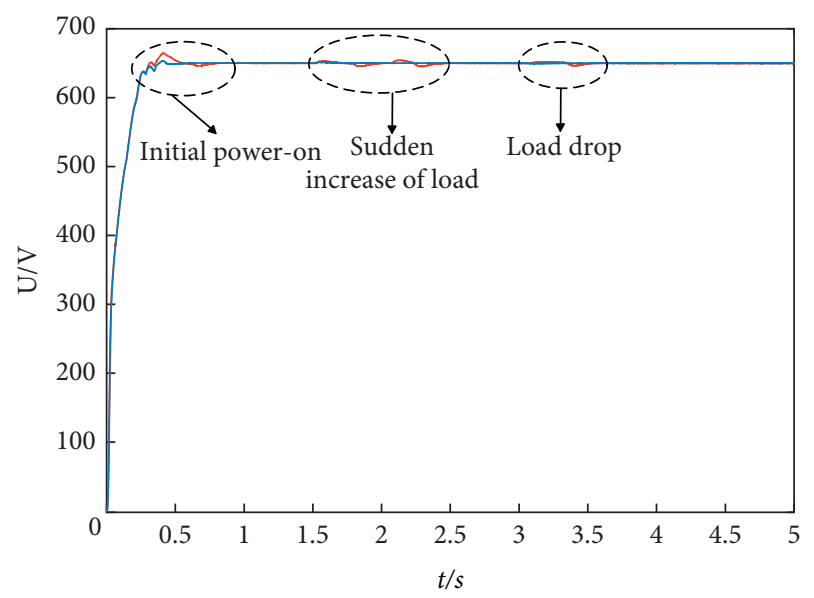

— Fuzzy double closed-loop control

— Adaptive genetic fuzzy double closed-loop control

FIgURE 9: Microgrid 2 bus voltage diagram.

Figures 11 and 13 are the bus voltage diagrams of microgrid 2 and microgrid 1 in fuzzy double closed loop and adaptive genetic fuzzy double closed loop, respectively.
Figures 12 and 14 are, respectively, enlarged views of three parts of initial power-on, load sudden increase, and load sudden decrease in Figures 11 and 13.

It can be seen from Figure 11 that when the energy storage converter adopts fuzzy double closed-loop control at the initial power-on, the maximum overshoot of the bus voltage is $12 \mathrm{~V}$. After oscillation adjustment, it stabilizes to $650 \mathrm{~V}$ in about $0.85 \mathrm{~s}$. When the energy storage converter adopts adaptive genetic fuzzy double closed-loop control, the maximum overshoot of the bus voltage is $3.3 \mathrm{~V}$. There is no oscillation during the recovery process, and it stabilizes to $650 \mathrm{~V}$ in about $0.75 \mathrm{~s}$. When the load suddenly increases, the bus voltage drops. When the energy storage converter adopts fuzzy double closed-loop control, the bus voltage drops to $639.8 \mathrm{~V}$ instantly. There is an overshoot phenomenon during the recovery process, and it stabilizes to $650 \mathrm{~V}$ in about $2.1 \mathrm{~s}$. When the energy storage converter adopts adaptive genetic fuzzy double closed-loop control, the bus voltage drops to 643.2 $\mathrm{V}$ instantly. There is no overshoot occurring during the recovery process, and it stabilizes to $650 \mathrm{~V}$ in about $2 \mathrm{~s}$. When the load drops suddenly, the bus voltage suddenly increases. When the energy storage converter adopts fuzzy double closed-loop control, the maximum overshoot of the 


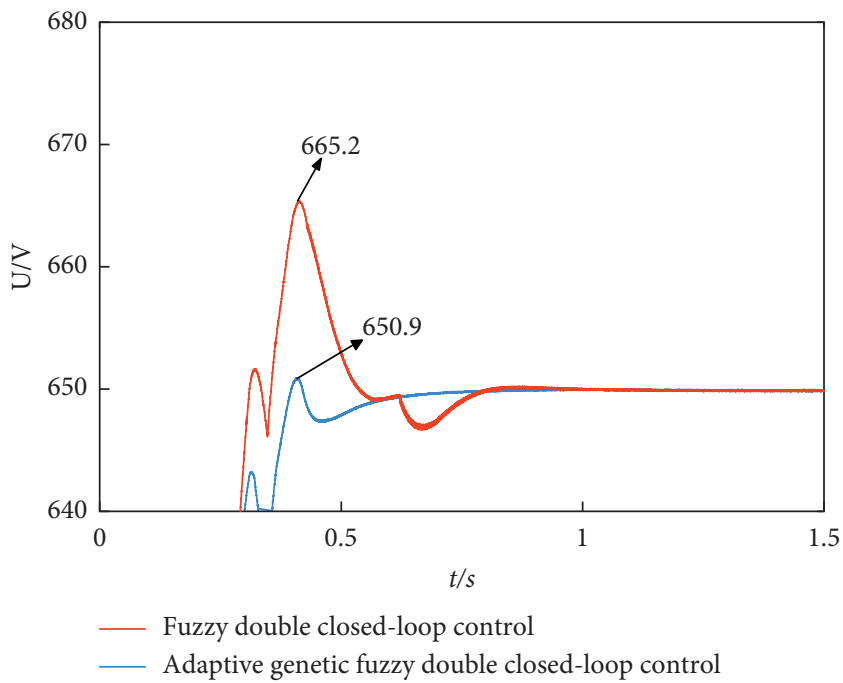

(a)

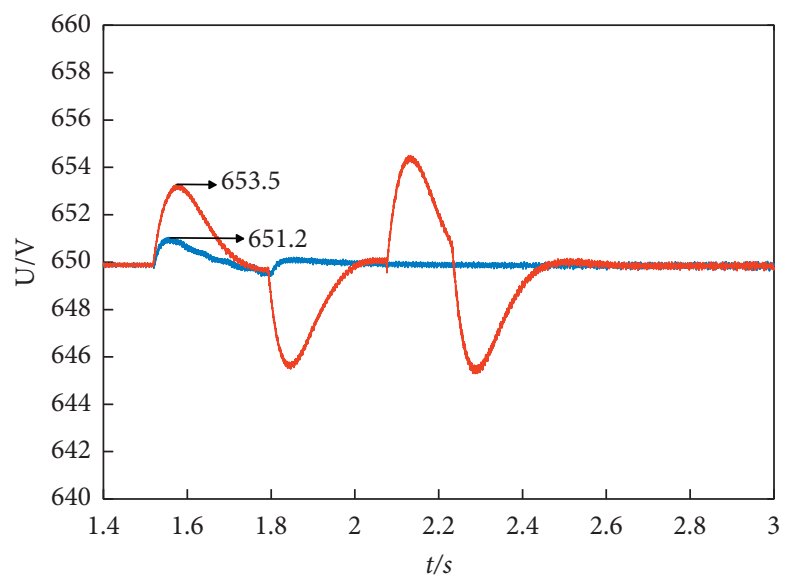

_ Adaptive genetic fuzzy double closed-loop control

(b)

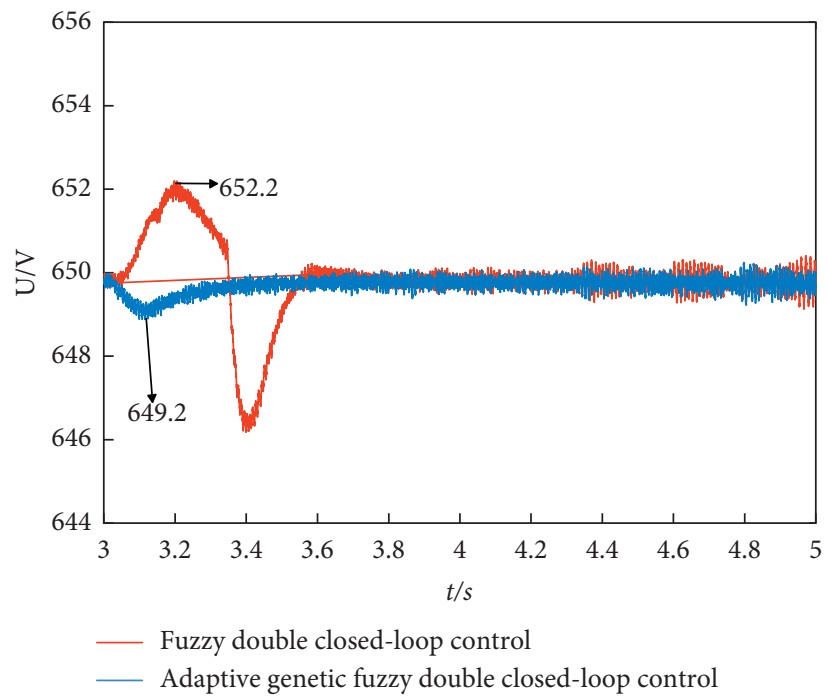

(c)

Figure 10: Voltage comparison of microgrid 2 bus. (a) Initial power-on. (b) Sudden increase of load. (c) A sudden drop in load.

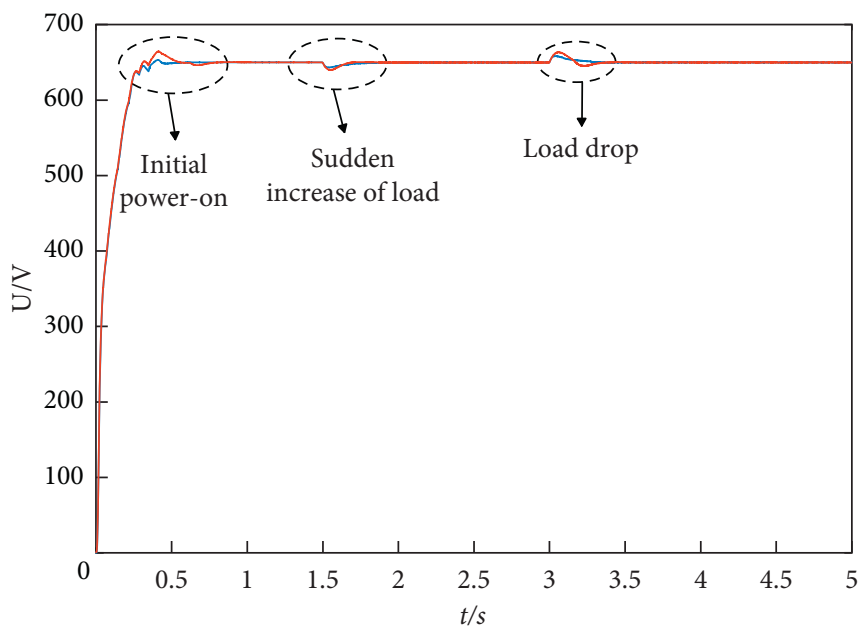

- Fuzzy double closed-loop control

— Adaptive genetic fuzzy double closed-loop control

FIgURE 11: Microgrid 2 bus voltage diagram. 


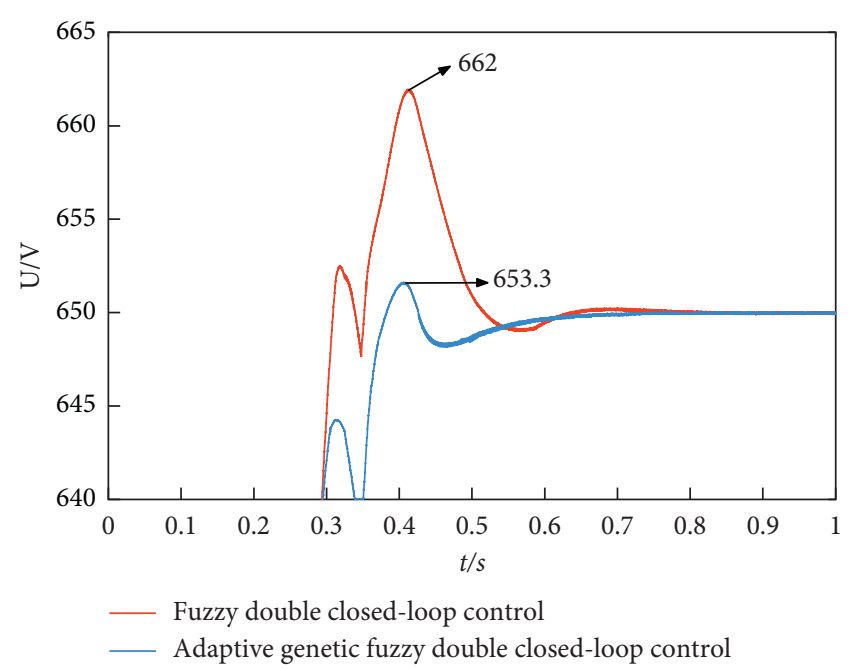

(a)

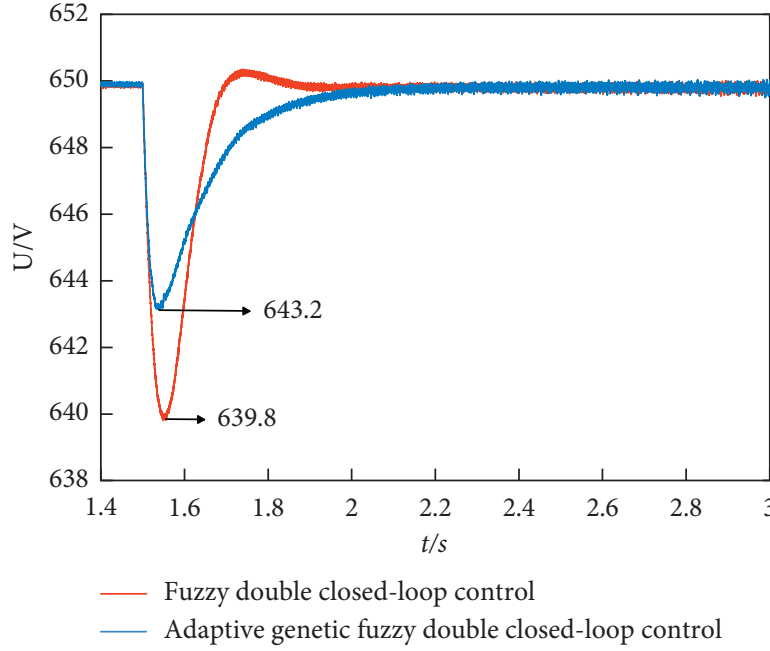

(b)

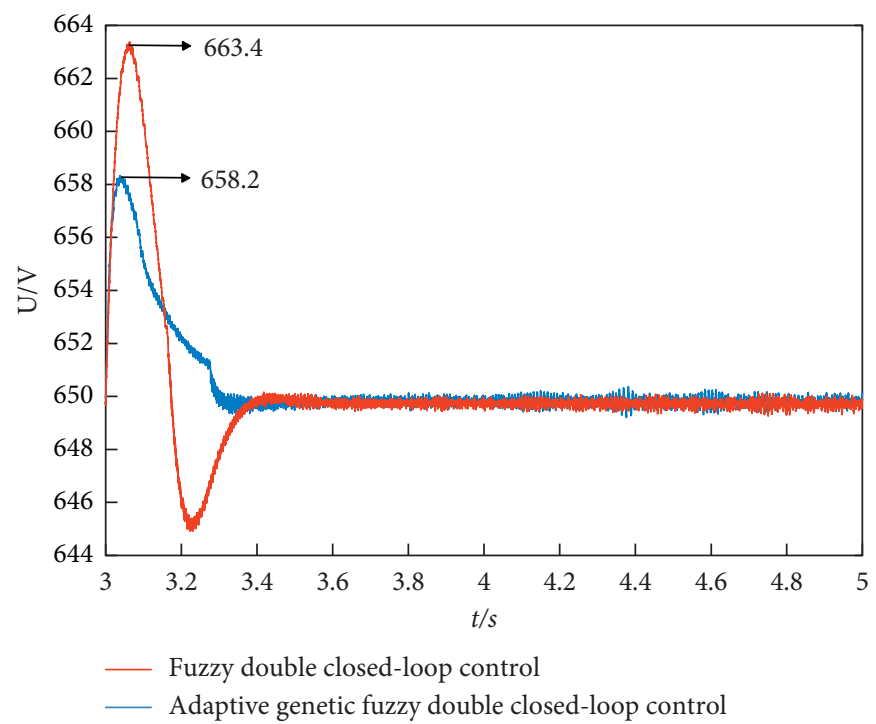

(c)

FIgURE 12: Voltage comparison of microgrid 2 bus. (a) Initial power-on. (b) Sudden increase of load. (c) A sudden drop in load.

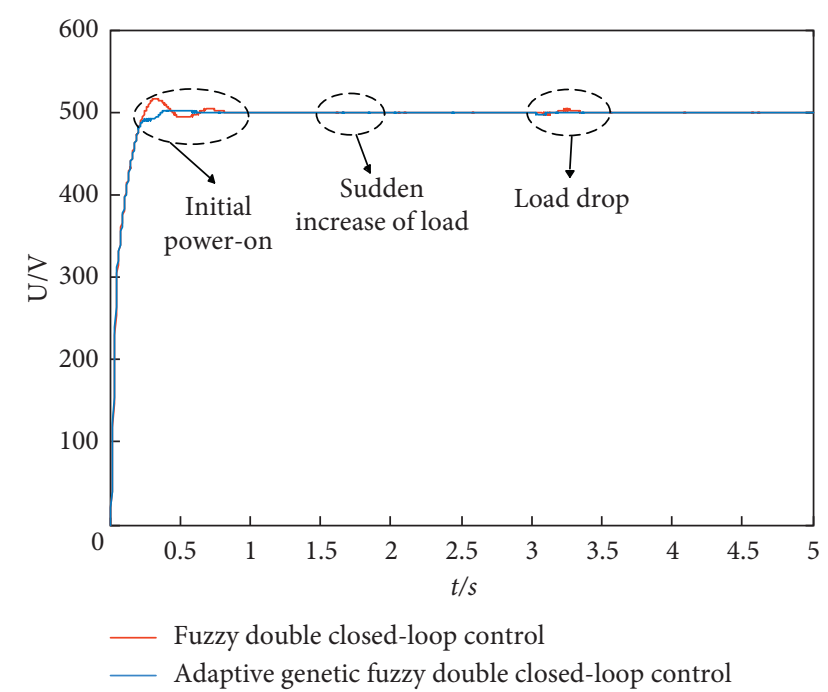

Figure 13: Microgrid 1 bus voltage diagram. bus voltage is $13.4 \mathrm{~V}$. After oscillation adjustment, it stabilizes to $650 \mathrm{~V}$ in about $3.6 \mathrm{~s}$. When the energy storage converter adopts the genetic fuzzy double closed-loop control, the maximum overshoot of the bus voltage is $8.2 \mathrm{~V}$. There is no oscillation during the recovery process, and it stabilizes to $650 \mathrm{~V}$ in about $3.25 \mathrm{~s}$.

It can be seen from Figure 10 that when the energy storage converter adopts fuzzy double closed-loop control at initial power-on, the maximum overshoot of the bus voltage is $17.5 \mathrm{~V}$. After oscillation adjustment, it stabilizes to $500 \mathrm{~V}$ in about $1.23 \mathrm{~s}$. When the energy storage converter adopts adaptive genetic fuzzy double closed-loop control, the maximum overshoot of the bus voltage is $2.1 \mathrm{~V}$. There is no oscillation phenomenon during the recovery process, and it stabilizes to $500 \mathrm{~V}$ around $0.92 \mathrm{~s}$. When the load increases suddenly, the energy storage converter adopts fuzzy double closed-loop control, and the overshoot of the bus voltage is $-0.8 \mathrm{~V}$. After oscillation adjustment, it stabilizes to $500 \mathrm{~V}$ in 


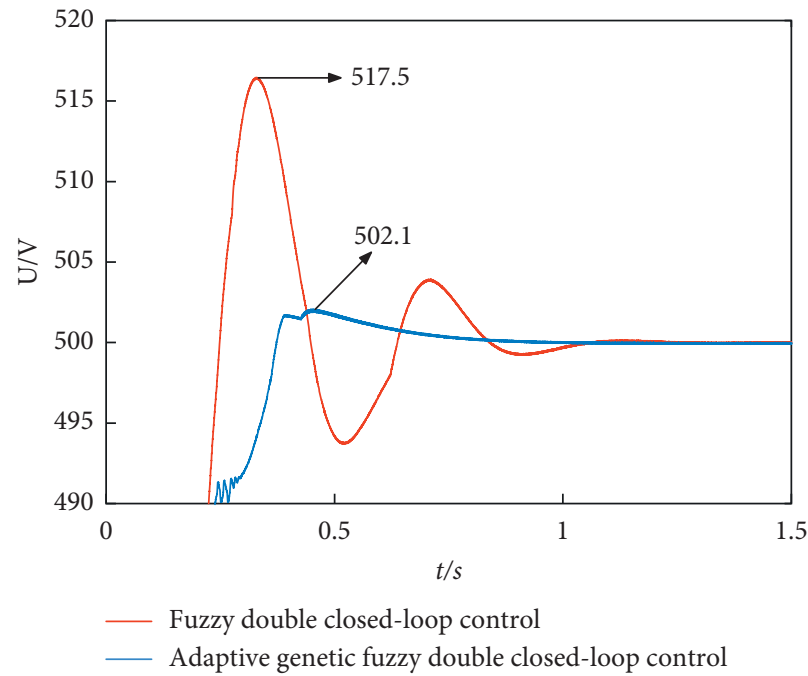

(a)

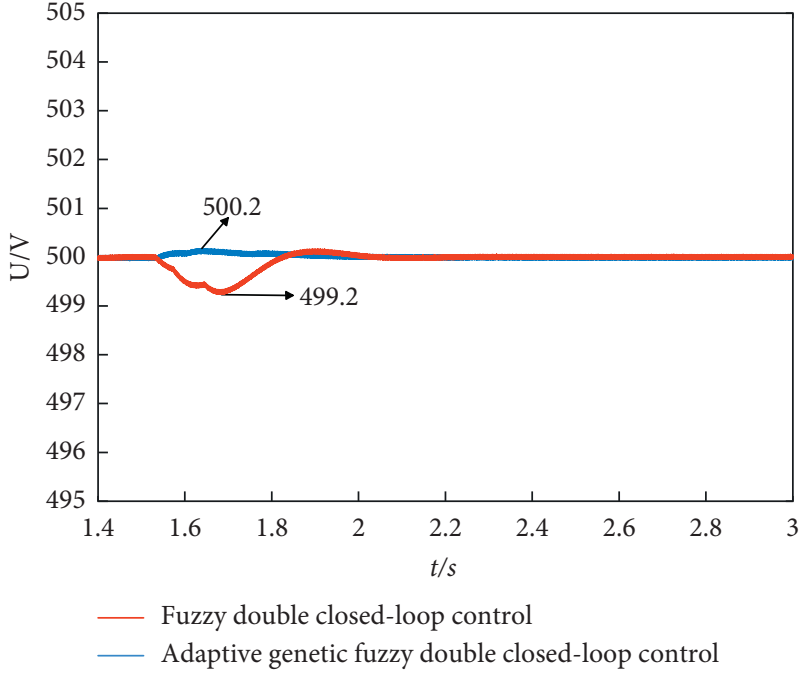

(b)

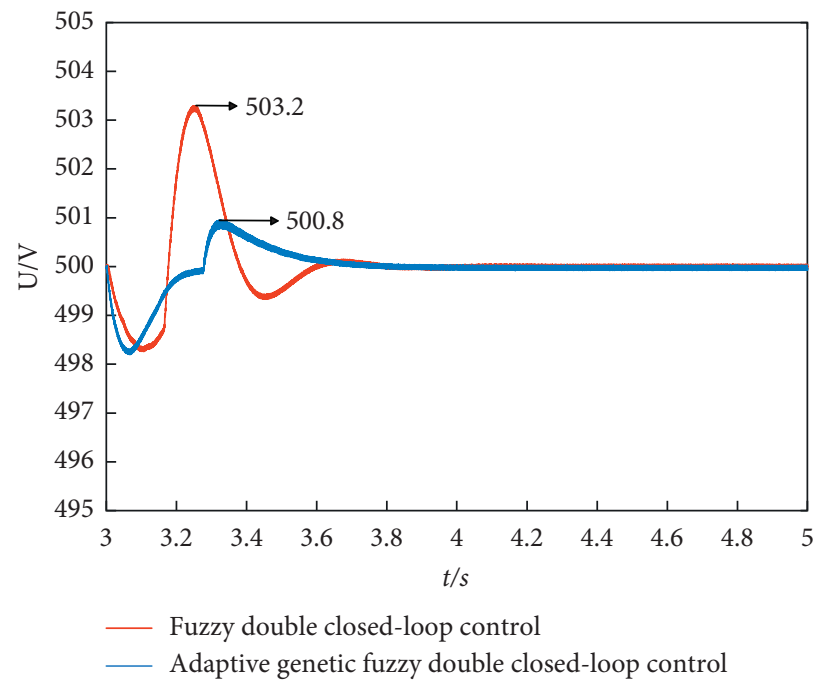

(c)

Figure 14: Voltage comparison of microgrid 1 bus. (a) Initial power-on. (b) Sudden increase of load. (c) A sudden drop in load.

about $2.2 \mathrm{~s}$. When the energy storage converter adopts adaptive genetic fuzzy double closed-loop control, the overshoot of the bus voltage is $0.2 \mathrm{~V}$. There is no oscillation occurring during the recovery process, and it stabilizes to $500 \mathrm{~V}$ around $1.85 \mathrm{~s}$. When the load is suddenly reduced, the energy storage converter adopts fuzzy double closed-loop control, and the overshoot of the bus voltage is $3.2 \mathrm{~V}$. After oscillation adjustment, it stabilizes to $500 \mathrm{~V}$ in about $4 \mathrm{~s}$. When the energy storage converter adopts adaptive genetic fuzzy double closed-loop control, the overshoot of the bus voltage is $0.8 \mathrm{~V}$. There is no oscillation during the recovery process, and it stabilizes to $500 \mathrm{~V}$ around $3.65 \mathrm{~s}$.

\section{Conclusion}

Aiming at the problems of bus voltage stabilization in the microgrid cluster, this paper adopts fuzzy double closedloop and adaptive genetic fuzzy double closed-loop control of the energy storage converters in the microgrid cluster, respectively. Studying the dynamic performance of the bus voltage during the three transient processes of the system initial power-on, the sudden increase of the load, and the sudden decrease of the load, according to the simulation analysis, the following conclusions are drawn:

(i) In the microgrid cluster, compared with the fuzzy double closed-loop control, the adaptive genetic fuzzy double closed-loop control can globally find the optimal value of the dynamically adjust quantization factors and scale factors, set the PI control parameters in real time, optimize the control effects, and enhance the micro robustness and stability of the network group system.

(ii) The interconnected microgrids in the microgrid cluster can achieve mutual energy transfer through the isolation BDC. So, when the bus voltage of a microgrid fluctuates, the bus voltage of the interconnected microgrid will also fluctuate, and the 
microgrid cluster system is in the BDC and the selfadjusting recovery is carried out under the joint action of the isolated BDC so that the system is restored to stability.

(iii) The simulation proves that, in the three different transient processes of the microgrid cluster system initial power-on, load sudden increase, and load sudden decrease, when the energy storage BDC adopts adaptive genetic fuzzy double closed-loop control, compared with fuzzy double closed-loop control, the system has not only a faster dynamic response, less overshoot, stronger anti-interference ability but also good robustness.

(iv) Adaptive genetic fuzzy double closed-loop control can be widely used in nonlinear and time-varying systems.

\section{Data Availability}

The data used to support the findings of this work are accessible from the corresponding author upon request.

\section{Conflicts of Interest}

The authors declare that they have no conflicts of interest.

\section{Acknowledgments}

This work was supported by the Natural Science Foundation of Guangxi (no. 2017GXNSFA A198161).

\section{References}

[1] Z. Lian and C. Deng, "Distributed security secondary control for cyber-physical microgrids systems under network DoS attacks," International Journal of Systems Science, vol. 52, no. 6, 2021.

[2] K. Ramesh and N. Sinha, "Voltage stability of solar dishStirling based autonomous DC microgrid using grey wolf optimised FOPID-controller," International Journal of Sustainable Energy, vol. 40, no. 5, 2021.

[3] M. Yazdanian and A. Mehrizi-Sani, "Distributed control techniques in microgrids," IEEE Transactions on Smart Grid, vol. 5, no. 6, pp. 2901-2909, 2014.

[4] S. Sandro and G. Fujita, "Impact of advanced load-frequency control on optimal size of battery energy storage in islanded microgrid system," Energies, vol. 14, no. 8, 2021.

[5] M. Chiandone, M. D. Feste, D. Bosich, and G. Sulligoi, "Realtime monitoring and control system for Trieste University campus electrical distribution grid," in Proceedings of the IEEE Milan PowerTech, pp. 1-5, Milan, Italy, June 2019.

[6] W. Huang, P. Wu, and N. Tai, "Flexible interconnected multimicrogrid structure and control method based on hybrid public connection unit," Proceedings of the CSEE, vol. 039, no. 12, pp. 3499-3513, 2019.

[7] ElH.. A. Bourouhou and A. D. Plasencia Lotufo, "Solar photovoltaic power forecasting," Journal of Electrical and Computer Engineering, vol. 2020, Article ID 8819925, , 2020.

[8] U. N. Ekanayake, U. S. Navaratne, and A. Bonfiglio, "A survey on microgrid control techniques in islanded mode," Journal of Electrical and Computer Engineering, vol. 2020, Article ID 6275460, , 2020.
[9] J. Mírez, "A modeling and simulation of optimized interconnection between DC microgrids with novel strategies of voltage, power and control," in Proceedings of the IEEE Second International Conference on DC Microgrids (ICDCM), pp. 536-541, Nuremburg, Germany, June 2017.

[10] M. He and M. Giesselmann, "Reliability-constrained selforganization and energy management towards a resilient microgrid cluster," in Proceedings of the IEEE Power \& Energy Society Innovative Smart Grid Technologies Conference (ISGT), pp. 1-5, Washington, DC, USA, February 2015.

[11] Z. Lei, F. Wang, Y. Gao, and Y. Ruan, "Research status and application 453 analysis of bidirectional DC-DC converters in DC micro-grids," Transactions 454 of China Electrotechnical Society, vol. 31, no. 22, pp. 137-147, 2016.

[12] P. Song and W. Zhu, "Virtual direct power control strategy of dual active 498 bridge DC-DC converter," Electrical Measurement \& Instrumentation, vol. 499, no. 5, pp. 125-131, 2018.

[13] Z. Wu, G. Hu, W. He, G. Hua, and C. Cai, "Research on simulation method for typical scenes of microgrid (group) access to distribution network," in Proceedings of the 2018 5th International Conference on Information Science and Control Engineering (ICISCE), pp. 491-495, Zhengzhou, China, July 2018.

[14] P. Ge, Y. Zhang, F. Wu, Y. An, and L. Zhou, "Stability control strategy of hybrid energy storage DC microgrid based on double closed loop," Heilongjiang Electric Power, Heilongjiang, China, vol. 41, no. 4, pp. 319-366, 2019.

[15] H. Liang, Y. Dong, and D. Cao, "Research on VSC-HVDC double closed loop controller based on variable universe fuzzy PID control," in Proceedings of the 2017 China International Electrical and Energy Conference (CIEEC), pp. 633-638, Beijing, China, October 2017.

[16] M. Xiaochun, W. Xiaohong, L. Yang, S. Shouxin, and Z. Chao, "Research on improvement of voltage fluctuation in microgrid based on improved double closed loop control of flywheel battery," in Proceedings of the 2019 IEEE 3rd Advanced Information Management, Communicates, Electronic and Automation Control Conference (IMCEC), pp. 1876-1880, Chongqing, China, October 2019.

[17] X. Wu, L. Zuo, J. Yi, and L. Han, "A double closed-loop control strategy for LCL-type grid-connected inverter based on combination state feedback," in Proceedings of the 2016 International Conference on Smart Grid and Clean Energy Technologies (ICSGCE), pp. 359-363, Chengdu, China, October 2016.

[18] Z. Zhixiong, Z. Yanzheng, L. Chih-Min, and H. Tao, “A fuzzy control framework for interconnected nonlinear power networks under TDS attack: estimation and compensation," Journal of the Franklin Institute, vol. 358, no. 1, 2021.

[19] E. Almodarresi, "Smooth velocity tracking and kinematicbased fuzzy control of carrying mobile robots," SN Applied Sciences, vol. 2, no. 12, 2020.

[20] V. Ablyazov, V. Ablyazov, O. Drachev, and V. Tisenko, "Fuzzy control under uncertainty in machine building," IOP Conference Series: Materials Science and Engineering, vol. 971, no. 2, 2020.

[21] Z. Liu, G. Fei, and Z. Chen, "Simulation study of double closed-loop spwm inverter based on fuzzy neural network," in Proceedings of the 2018 IEEE 3rd Advanced Information Technology, Electronic and Automation Control Conference (IAEAC), pp. 241-245, Chongqing, China, October 2018.

[22] Y. Lu, "Adaptive-fuzzy control compensation design for direct adaptive fuzzy control," IEEE Transactions on Fuzzy Systems, vol. 26, no. 6, pp. 3222-3231, 2018. 
[23] Z. Jie, H. Long, and R. Sijing, "RBF neural network adaptive sliding mode control based on genetic algorithm optimization," in Proceedings of the 2016 Chinese Control and Decision Conference (CCDC), pp. 6772-6775, Yinchuan, China, May 2016.

[24] Z. Peng, "PID control of temperature and humidity in granary based on improved genetic algorithm," in Proceedings of the 2019 IEEE International Conference on Power, Intelligent Computing and Systems (ICPICS), p. 428, Shenyang, China, July 2019.

[25] Yu Zhe, W. Zhiguo, and L. Fei, "Optimization of fuzzy internal model PID controller based on genetic algorithm," Control and Instruments in Chemical Industry, vol. 47, no. 4, pp. 294-321, 2020. 